\section{International Scientific Journal Theoretical \& Applied Science}

p-ISSN: 2308-4944 (print) e-ISSN: 2409-0085 (online)

Year: $2017 \quad$ Issue: 12 Volume: 56

Published: $30.12 .2017 \quad$ http://T-Science.org
Asli Khanguseyn Kazymova

Doctor of Philosophy in Economics, Senior lecturer of the department "Regulation of Economics"

Azerbaijan State Economic University, Azerbaijan Republic

SECTION 19. Management. Marketing. Public administration.

\title{
THE PROBLEMS AND MECHANISMS OF REGULATION OF ACTIVITY OF NON-TERRITORY SPHERES OF INDUSTRY OF AZERBAIJAN IN CONTEXT STRATEGIC ROAD MAPS
}

Abstract: The problems and mechanisms of regulation of activity of non-territory spheres of industry of Azerbaijan in context strategic road maps are studied in the article. The potential and rationality of the activities of non-oil industrial spheres in the context of current requirements are analyzed. The problems of intensification of development of individual non-oil sectors of industry, such as metallurgical, chemical and petrochemical, machine building complex, light and food industries are considered. The importance of accelerating the modernization of certain spheres of the non-oil industry of the country is substantiated through the use of modern technologies and attraction of foreign investments. A number of proposals and recommendations on the problems and mechanisms for regulating the activities of the non-oil industry in Azerbaijan in the context of strategic road maps are given at the end of the article

Key words: non-oil industries of Azerbaijan, the potential of the industry of Azerbaijan, modernization of nonoil industrial spheres, strategic goals and tasks of the non-oil sphere of industry of Azerbaijan, intensification of development of non-agricultural industries

Language: Russian

Citation: Kazymova AK (2017) THE PROBLEMS AND MECHANISMS OF REGULATION OF ACTIVITY OF NON-TERRITORY SPHERES OF INDUSTRY OF AZERBAIJAN IN CONTEXT STRATEGIC ROAD MAPS. ISJ Theoretical \& Applied Science, 12 (56): 157-164.

Soi: http://s-0-i.org/1.1/TAS-12-56-25 Doi: roskef https://dx.doi.org/10.15863/TAS.2017.12.56.25

\section{ПРОБЛЕМЫ И МЕХАНИЗМЫ РЕГУЛИРОВАНИЯ ДЕЯТЕЛЬНОСТИ НЕНЕФТЯНЫХ СФЕР ПРОМЫШЛЕННОСТИ АЗЕРБАЙДЖАНА В КОНТЕКСТЕ СТРАТЕГИЧЕСКОЙ ДОРОЖНОЙ КАРТЫ}

\begin{abstract}
Аннотация: В статье исследованы проблемы и механизмы регулирования деятельности ненефтяной сферы промышленности Азербайджана в контексте стратегических дорожных карт в условиях роста глобальных угроз. Анализирован потенциал и повышение рациональности деятельности ненефтяных промышленных сфер в контексте нынешних требований. Рассмотрены проблемы интенсификации развития отдельных ненефтяных секторов промышленности, таких как металлургический, химический и нефтехимический, машиностроительный комплекс, легкая и пищевая промышленности. Обоснована важность ускорения модернизация отдельных сфер ненефтяных промышленностей страны за счет применений современных технологий и привлечения иностранных инвестиций. Дан ряд предложений и подготовлены рекомендации по проблемам и механизмам регулирования деятельности ненефтяных сфер промышленности Азербайджана в контексте стратегических дорожных карт.

Ключевые слова: ненефтяные сферы промышленности Азербайджана, потенциал промышленности Азербайджана, модернизация ненефтяных промышленных сфер, стратегические цели и задачи ненефтяных сфер промышленности Азербайджана, интенсификация развития ненефтяных сфер промышленности Азербайджана.
\end{abstract}

\section{Introduction}

Проблема развития ненефтяных секторов экономики Азербайджана является одной из важнейших задач правительства страны по расширению структуры национальной экономики и повышения эффективности в целом

ISPC Generalization of scientific results, 
экономической модели страны в условиях роста глобальных угроз и глобальных тенденций развития мировых экономических процессов. Азербайджан, после восстановления своей независимости, добился немалого успеха по проведению экономических реформ, созданию и развитию рыночных инфраструктур и особенно удалось интенсивное развитие добывающей отрасли, то есть добычи нефти и газа. Осуществлены основные фазы и этапы экономических реформ, и формирование современного атрибута независимого государства, в том числе обеспечение развития институциональных органов государство. Однако с усилением негативных последствий мирового финансового кризиса и нестабильности цен энергоносителей на мировых рынках, в том числе основных экспортных продукций Азербайджана, сырой нефти и природного газа, страна испытывает нехватку притока валютных средств. Тем самым требуется расширение источника валютных поступлений извне за счет конкурентоспособных экспортноориентировочных продукций ненефтяных секторов промышленности [1].

\section{Materials and Methods}

Следует отметить, что ненефтяные секторы Азербайджана за последние годы стали играть важную роль в формировании роста добавочной стоимости в экономике страны.

На Рисунке 1 дана развернутая структура добавочной стоимости, сформированная в ненефтяной промышленности Азербайджана за 2016 год.

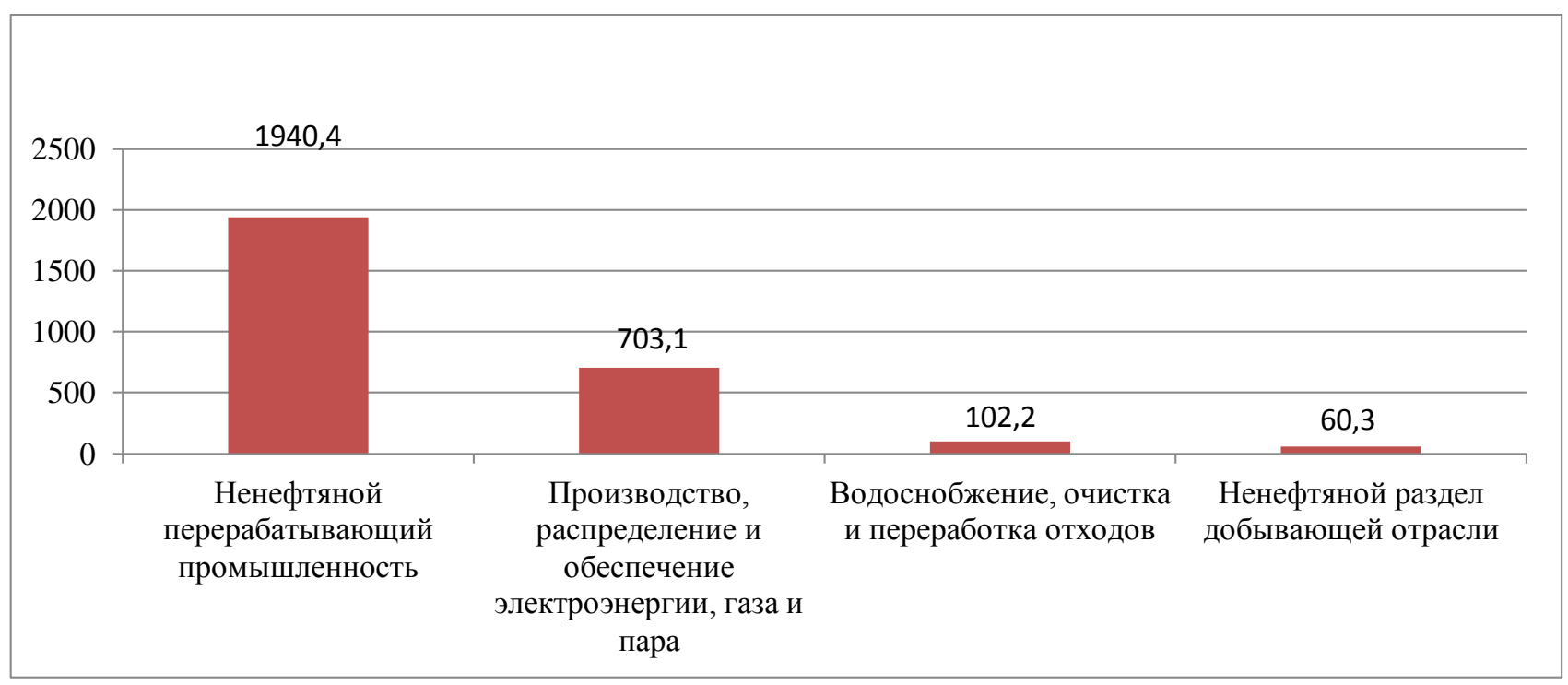

Рисунок 1 - Структура добавочной стоимости, сформированной в ненефтяной промышленности
Азербайджана за 2016 год, млн. манат (Разработано автором на основе статистических изданий
Государственного Статистического Комитета Азербайджанской Республики. http://www.stat.gov.az)

В связи с расширением создания сети инфраструктуры в регионах страны и в рамках развития отдаленных местностей страны, растет доля продукции производства энергоносителей, их распределение и обеспечение.
На Рисунке 2 даны рост ненефтяного сектора страны к предыдущему году. 


\begin{tabular}{l|lr|ll|ll} 
& ISRA (India) & $=\mathbf{1 . 3 4 4}$ & SIS (USA) & $=\mathbf{0 . 9 1 2}$ & ICV (Poland) & $=\mathbf{6 . 6 3 0}$ \\
Impact Factor: & ISI (Dubai, UAE) $=\mathbf{0 . 8 2 9}$ & PUHЦ (Russia) $=\mathbf{0 . 2 0 7}$ & PIF (India) & $=\mathbf{1 . 9 4 0}$ \\
& GIIF (Australia) & $=\mathbf{0 . 5 6 4}$ & ESJI (KZ) & $=4.102$ & IBI (India) & $=4.260$ \\
& JIF & $=\mathbf{1 . 5 0 0}$ & SJIF (Morocco) & $=\mathbf{2 . 0 3 1}$ & & \\
\hline
\end{tabular}

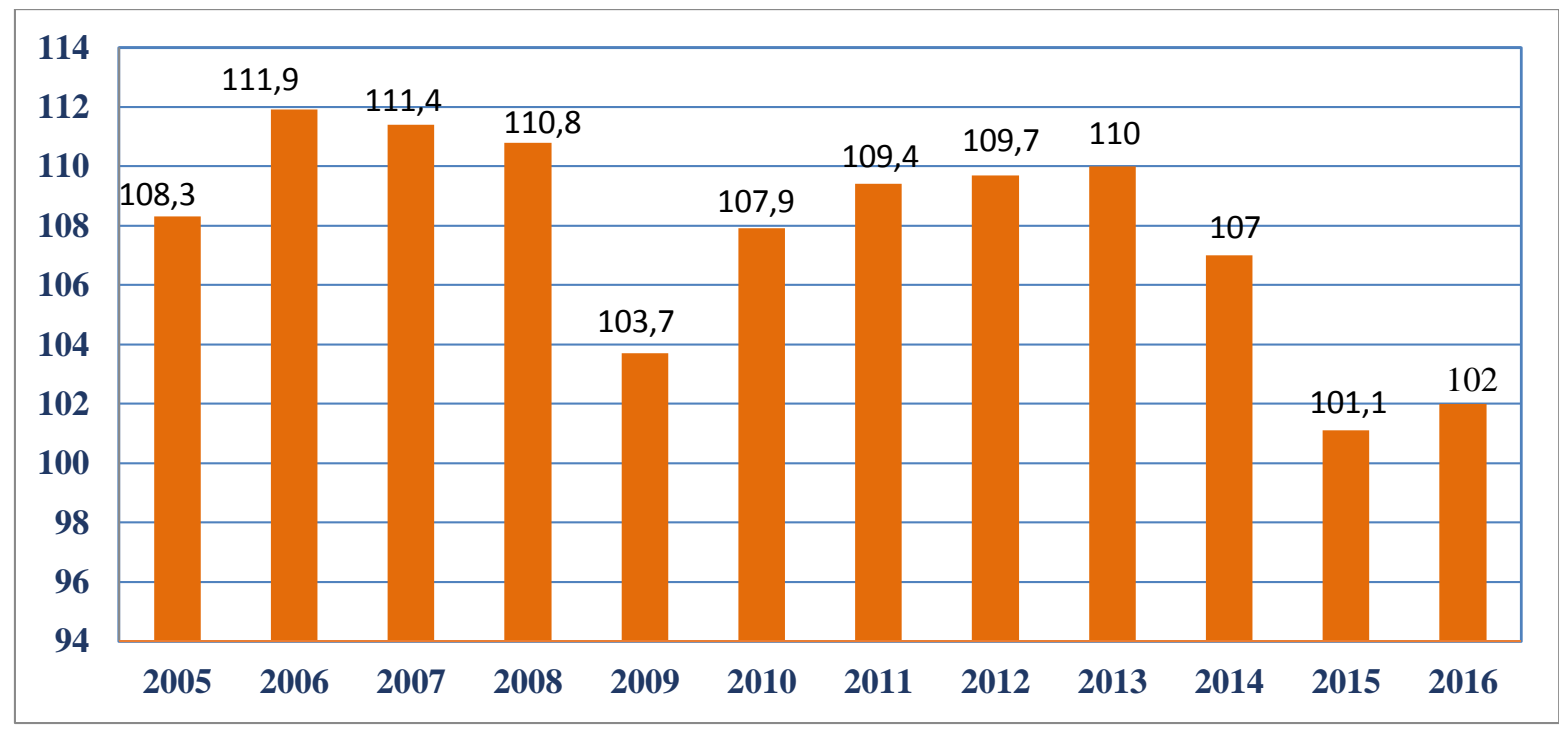

Рисунок 2 - Рост ненефтяного сектора Азербайджанской Республики к предыдущему году, в процентах (Разработано автором на основе статистических изданий Государственного Статистического Комитета Азербайджанской Республики. http://www.stat.gov.az).

Как видно из Рисунка 2, за последние годы рост ненефтяного сектора столь невелик, однако в 2016-ом году удалось обеспечить небольшой рост по отношению к 2015-му году. То есть, можно сделать вывод, что после негативных последствий мировых экономических процессов и глобализаций тенденция падения в ненефтяном секторе Азербайджана приостановлена и созданы соответствующие основы для восстановления его динамики роста. Для этого в Азербайджане проводятся огромные работы по преобразованию системы управления и прочих институциональноорганизационных мероприятий по обеспечению ускорения развития разных ненефтяных секторов промышленности, в том числе в сфере тяжелой промышленности [2;3;4;5]. Например, в Азербайджане заново формируется потенциал металлургического комплекса и одновременно создаются крупные современные предприятия по производству металлургических продукций сразу в обеих сферах металлургического комплекса, то есть в черной и цветной металлургии. В основных промышленных центрах страны - в городах Сумгайыт и Гянджа строится металлургические установки на основе современных технологий [6]. В Гяндже создан целый металлургический комплекс и обеспечивается производством первичных назначений, то есть основными сырьевыми ресурсами металлургической промышленности. А в Сумгайыте на базе ОАО «Азербору» (Азерпровод) создается крупный металлургический кластер, у которого нет в регионе аналога такого крупномасштабного металлургического комплекса. Объем вложенных инвестиций в данную сферу достиг суммы 1,5-2,0 млрд. долларов США. С полной активизацией металлургического комбината, Азербайджан обеспечит себе высококачественные металлургические изделия и одновременно станет крупнейшим экспортером аналогичной продукции в регионе.

На Рисунке 3 дана динамика производства продукции металлургической промышленности Азербайджанской Республики за 2011-2016 годы.
ISPC Generalization of scientific results, 


\begin{tabular}{|c|c|c|c|c|c|c|}
\hline Impact Factor: & $\begin{array}{l}\text { ISRA (India) } \\
\text { ISI (Dubai, UAE } \\
\text { GIF (Australia) } \\
\text { JIF }\end{array}$ & $\begin{array}{l}=1.344 \\
=0.829 \\
=0.564 \\
=1.500\end{array}$ & $\begin{array}{l}\text { SIS (USA) } \\
\text { PИНЦ (Russia } \\
\text { ESJI (KZ) } \\
\text { SJIF (Morocco }\end{array}$ & $\begin{aligned}= & 0.912 \\
= & 0.207 \\
= & 4.102 \\
= & 2.031\end{aligned}$ & $\begin{array}{l}\text { ICV (Poland) } \\
\text { PIF (India) } \\
\text { IBI (India) }\end{array}$ & $\begin{array}{l}=6.630 \\
=1.940 \\
=4.260\end{array}$ \\
\hline
\end{tabular}

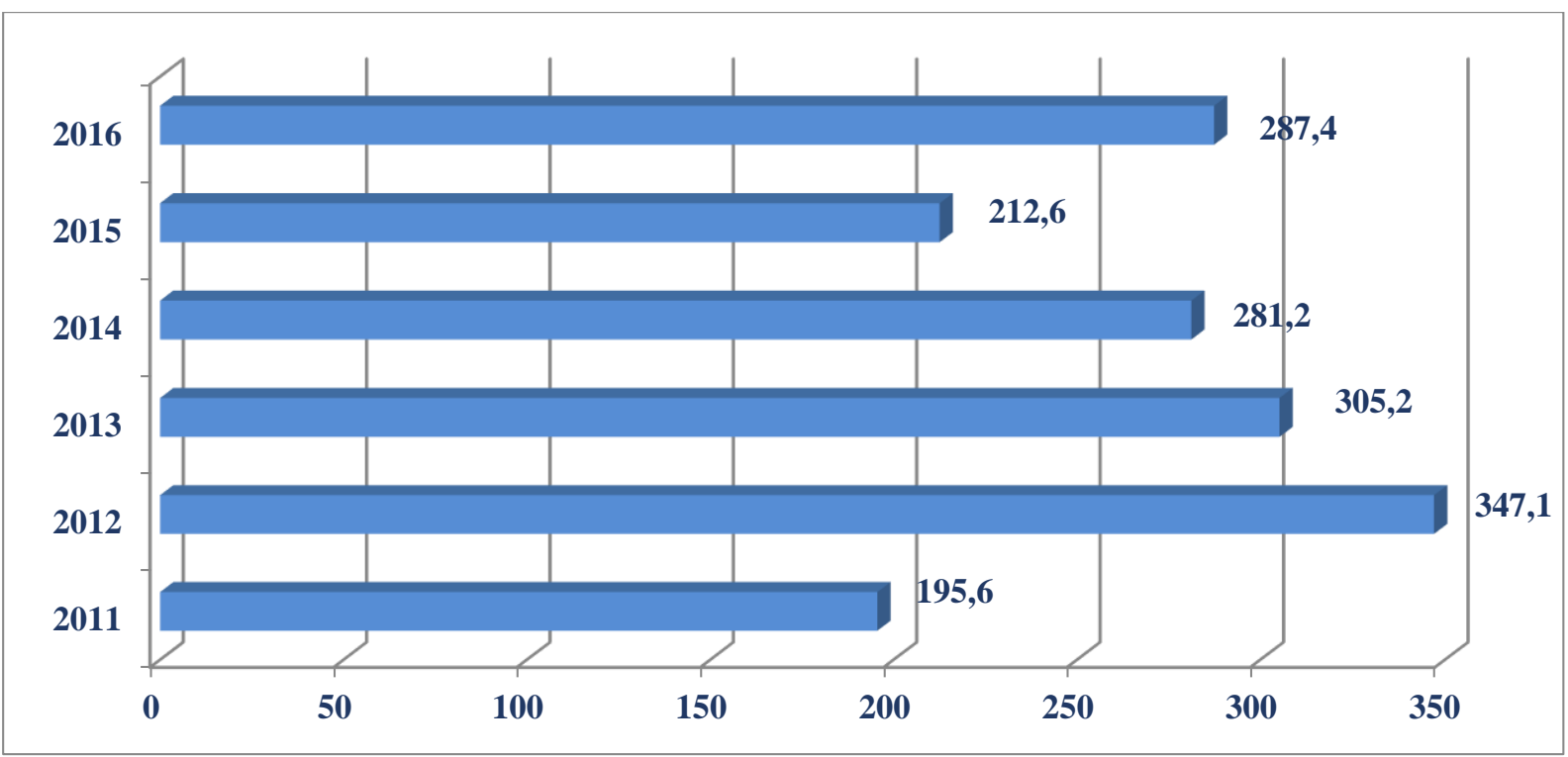

Рисунок 3 - Динамика производства продукции металлургической промышленности

Азербайджанской Республики за 2011-2016 годах, млн. манат (Разработано автором на основе статистических изданий Государственного Статистического Комитета Азербайджанской Республики. http://www.stat.gov.az).

На основе Рисунка 3 можно сделать вывод, что за 2014-2016 годы выпуск производства металлургической продукции находится почти на одном уровне. Однако после падения выпуска продукции в 2015 году по отношению к 2014-му году, в последующем 2016-ом году был восстановлен объем продукции и даже отмечен незначительный рост выпуска продукции в металлургической промышленности Азербайджана.

Отметим крупный потенциал еще одной сферы ненефтяного сектора промышленности химического и нефтехимического комплекса. Данная отрасль в Азербайджане имеет давнюю историю и тесно связано с развитием нефтяной промышленности. Еще в бытности состава бывшего СССР в Азербайджане функционировали крупнейшие химические и нефтехимические заводы и комбинаты. Их продукция экспортировалось в сотни городов и во многие регионы бывшего СССР. Однако тогда важными факторами и значением являлись тесные кооперационные связи между крупными предприятиями и союзными республиками $\mathrm{CCCP}$, и одновременно планировалось производство, распределение ресурсов и в том числе поставка готовой продукции по годовым разнарядкам, подготовленным и отправленным из центра - из Москвы. А сейчас химическим и нефтехимическим предприятиям Азербайджана приходиться развиваться на рыночных основах и выдержать влияние конкурентной среды на мировых рынках.

На Рисунке 4 дана динамика общего объема выпуска продукции в химической промышленности Азербайджана за 2011-2016 годы. 


\begin{tabular}{l|lr|ll|ll} 
& ISRA (India) & $=\mathbf{1 . 3 4 4}$ & SIS (USA) & $=\mathbf{0 . 9 1 2}$ & ICV (Poland) & $=\mathbf{6 . 6 3 0}$ \\
Impact Factor: & ISI (Dubai, UAE) & $=\mathbf{0 . 8 2 9}$ & PUHL (Russia) & $=\mathbf{0 . 2 0 7}$ & PIF (India) & $=\mathbf{1 . 9 4 0}$ \\
& GIIF (Australia) & $\mathbf{0 . 5 6 4}$ & ESJI (KZ) & $=\mathbf{4 . 1 0 2}$ & IBI (India) & $\mathbf{4 . 2 6 0}$ \\
& JIF & $=\mathbf{1 . 5 0 0}$ & SJIF (Morocco) & $=\mathbf{2 . 0 3 1}$ & & \\
\hline
\end{tabular}

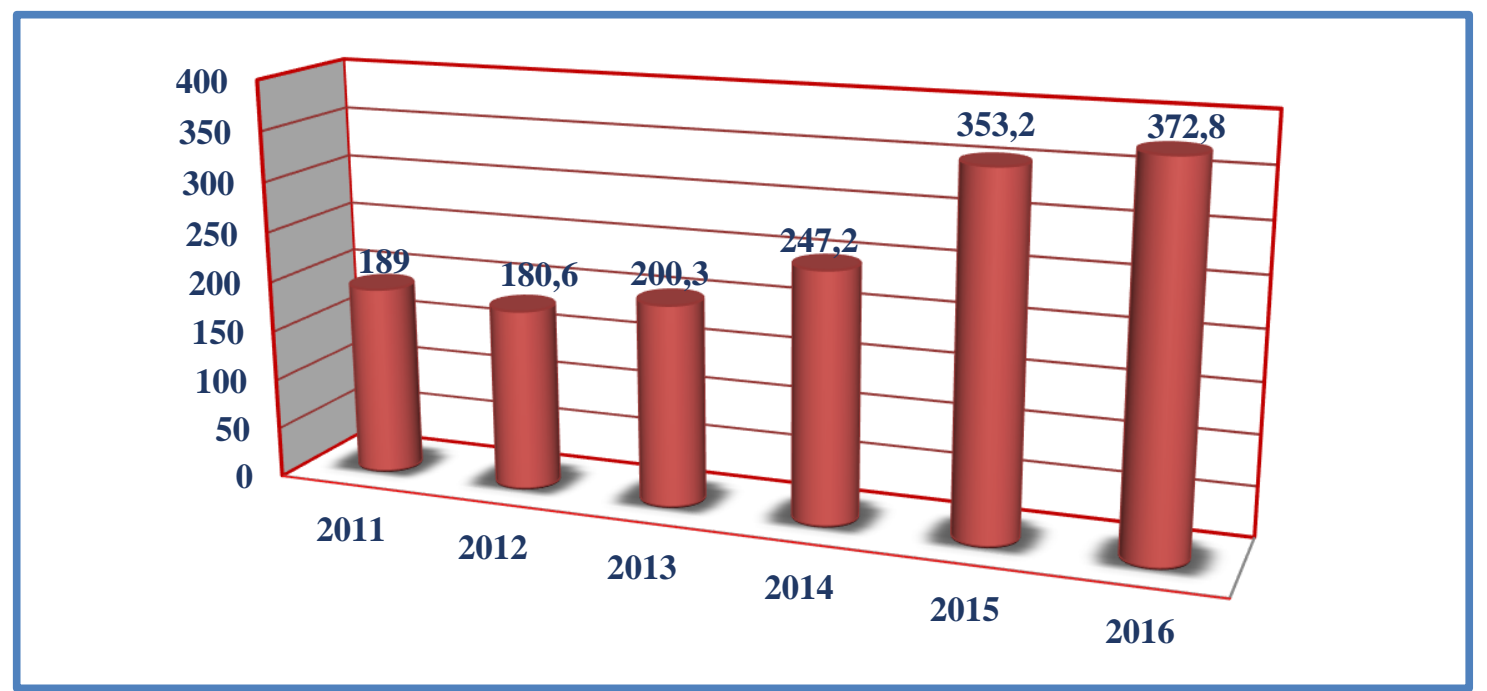

Рисунок 4- Динамика общего объема выпуска продукции в химической промышленности Азербайджана за 2011-2016 годы, млн. манат (Разработано автором на основе статистических изданий Государственного Статистического Комитета Азербайджанской Республики. http://www.stat.gov.az).

Анализ Рисунка 4 показывает, что за период 2011-2016 годы рост производства химической продукции вырос почти в 2 раза и, по итогам 2016 года составил 372,8 млн. манат или примерно 222 млн. долларов США. Отметим, что за последние годы стал осуществляться ряд крупных проектов по строительству химических установок и заводов [7]. Например, в ближайшее время ожидается сдача в эксплуатацию современных производств по карбамидам, полипропиленам, полиэтиленам низких давлений и т.д. В результате расширения потенциала химической и нефтехимической промышленности Азербайджана экспортные возможности сферы повысились на уровень примерно 700-800 млн. долларов США в год.

В Азербайджане одной из перспективных сфер ненефтяного сектора промышленности является машиностроительный комплекс. В данной сфере производятся различные оборудования и инвентари, фитинги и прочие оборудования для нефтегазодобычи. В предприятиях машиностроительного комплекса Азербайджана производиться свыше 100 оборудований различного наименования и 500 различных размеров, профилей разных оборудований и изделий для нефтегазодобывающих отраслей [8]. Однако основные предприятия данной отрасли нуждаются в реконструкции и модернизации, так как многие из них не выдерживают конкурентной среды и работают значительно ниже своих возможностей.

На Рисунке 5 дана динамика выпуска продукции предприятия промышленности машиностроения Азербайджанской Республики за 2011-2016 годы. 


\begin{tabular}{l|lr|ll|ll} 
& ISRA (India) & $=\mathbf{1 . 3 4 4}$ & SIS (USA) & $=\mathbf{0 . 9 1 2}$ & ICV (Poland) & $=\mathbf{6 . 6 3 0}$ \\
Impact Factor: & ISI (Dubai, UAE) $=\mathbf{0 . 8 2 9}$ & PUHЦ (Russia) $=\mathbf{0 . 2 0 7}$ & PIF (India) & $=\mathbf{1 . 9 4 0}$ \\
& GIF (Australia) & $\mathbf{0 . 5 6 4}$ & ESJI (KZ) & $=\mathbf{4 . 1 0 2}$ & IBI (India) & $=\mathbf{4 . 2 6 0}$ \\
& JIF & $=\mathbf{1 . 5 0 0}$ & SJIF (Morocco) & $=\mathbf{2 . 0 3 1}$ & & \\
\hline
\end{tabular}

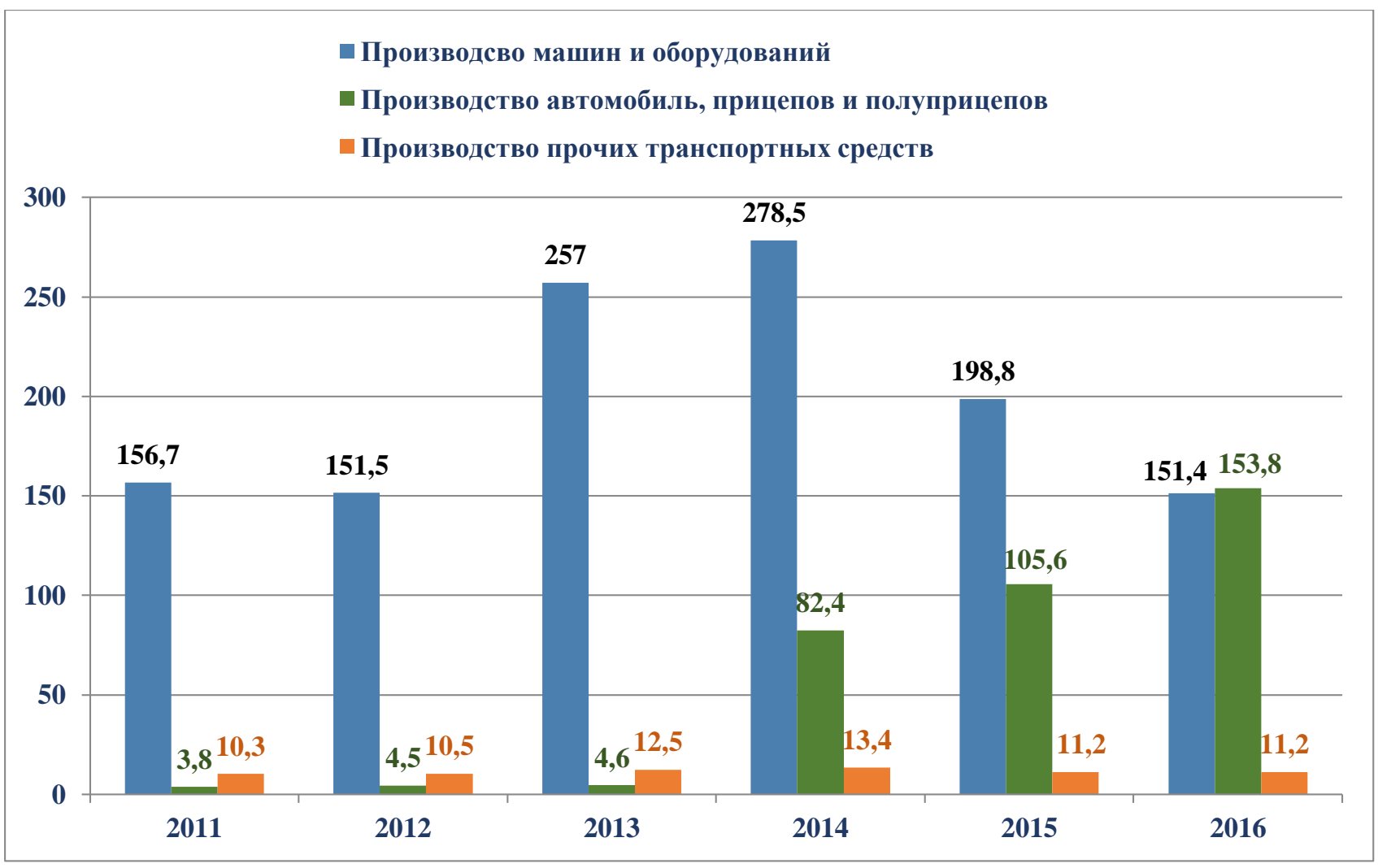

Рисунок 5 - Динамика выпуска продукции предприятия промышленности машиностроение Азербайджанской Республики за 2011-2016 годы (Разработано автором на основе статистических изданий Государственного Статистического Комитета Азербайджанской Республики. http://www.stat.gov.az).

Как видно, из Рисунка 5 за последние годы объем продукции по производству машин и оборудования резко упал, а производство автомобилей прицепов и полуприцепов продемонстрировал рост, производство прочих транспортных средств остались на одном уровне. Все эти факты обуславливают глубокое изучение существующих проблем, мешающих в интенсификации развития предприятия промышленности машиностроения, и обеспечить их обновление, модернизацию и конкурентоспособность для выхода на внешний рынок.
В Азербайджане имеется ряд сфер ненефтяного сектора промышленности, которые считаются традиционными для страны, и имеют огромное значение для развития сельских местностей, регионов и обеспечения занятости, одновременно способствуют решению социально-экономических проблем, помогают повышению потребительского уровня населения, усилению продовольственной безопасности. К таким сферам относятся легкие и пищевые промышленности Азербайджана.

На Рисунке 6 дана динамика выпуска продукции в сфере легкой промышленности в Азербайджане за 2011-2016 годы. 


\begin{tabular}{l|lr|ll|ll} 
& ISRA (India) & $=\mathbf{1 . 3 4 4}$ & SIS (USA) & $=\mathbf{0 . 9 1 2}$ & ICV (Poland) & $=\mathbf{6 . 6 3 0}$ \\
Impact Factor: & ISI (Dubai, UAE) $=\mathbf{0 . 8 2 9}$ & PUHЦ (Russia) $=\mathbf{0 . 2 0 7}$ & PIF (India) & $=\mathbf{1 . 9 4 0}$ \\
& GIF (Australia) & $=\mathbf{0 . 5 6 4}$ & ESJI (KZ) & $=4.102$ & IBI (India) & $=\mathbf{4 . 2 6 0}$ \\
& JIF & $=\mathbf{1 . 5 0 0}$ & SJIF (Morocco) & $=\mathbf{2 . 0 3 1}$ & & \\
\hline
\end{tabular}

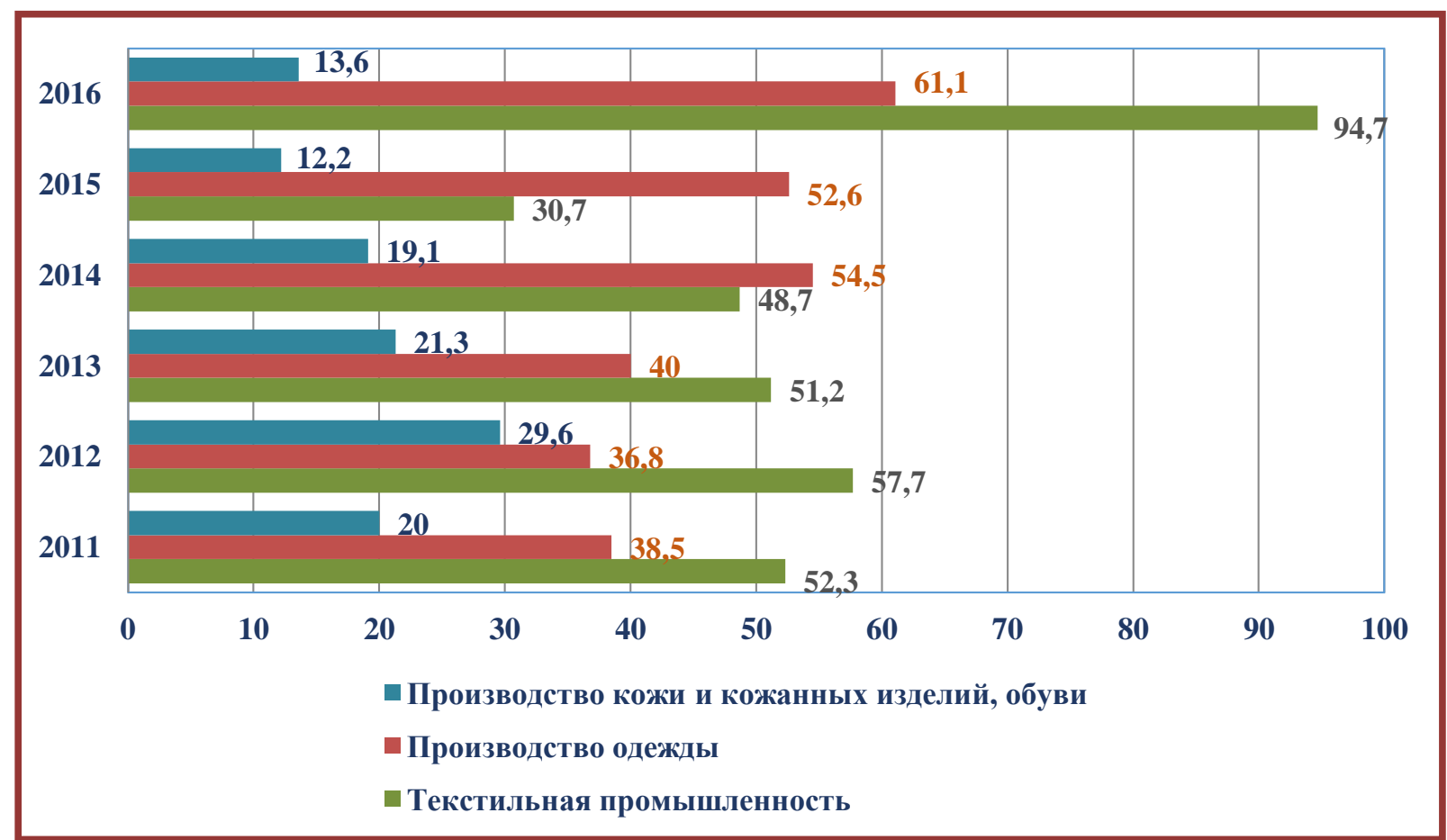

Рисунок 6 - Динамика выпуска продукции в сфере легкой промышленности в Азербайджане за 20112016 годы, млн. манат (Разработано автором на основе статистических изданий Государственного

Статистического Комитета Азербайджанской Республики. http://www.stat.gov.az.).

Отметим, что объем и динамика выпуска в сфере легкой промышленности в Азербайджане находиться ниже своих возможностей, так как для развития и расширения всех сфер данной отрасли в стране имеется достаточные ресурсы и условия [9;10]. Однако пока особые успехи этих сфер не обеспечены и в ближайшей перспективе придется выложить немалые усилия по интенсификации развития данной отрасли.

На Рисунке 7 отражена динамика выпуска пищевых продукций в пищевой промышленности Азербайджана.

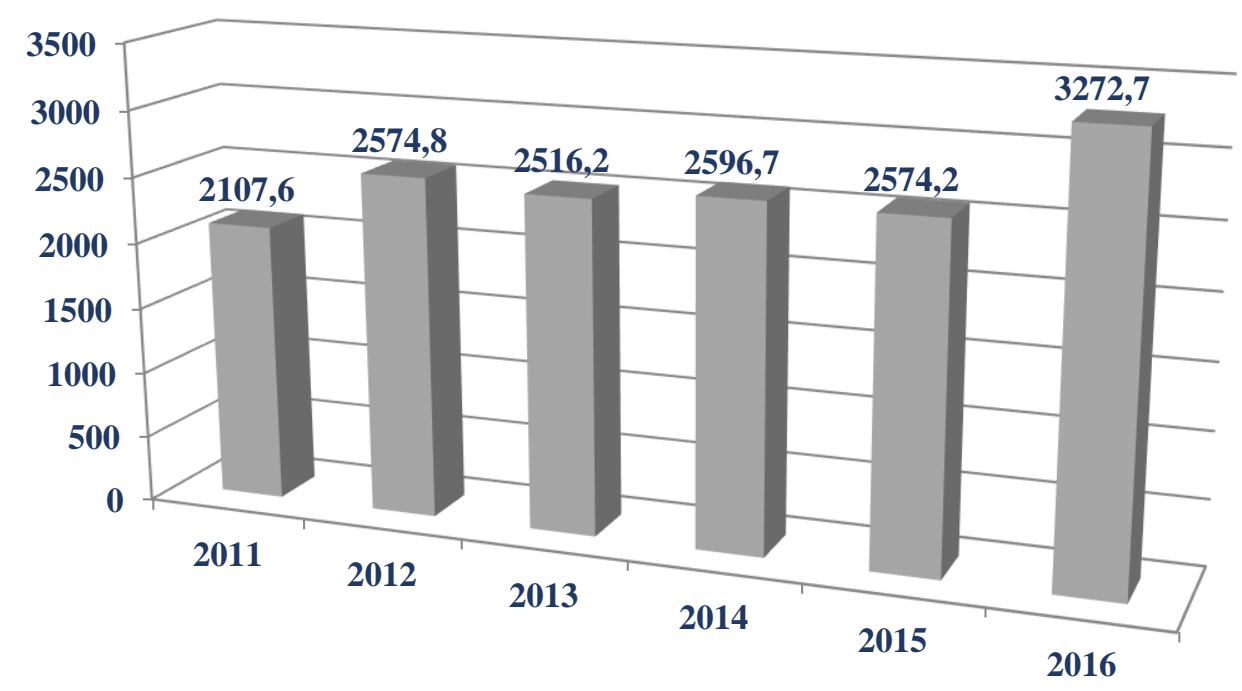

Рисунок 7 - Динамика выпуска пищевых продукций в пищевой промышленности Азербайджанской Республики за 2011-2016 годы, млн. манат (Разработано автором на основе статистических изданий Государственного Статистического Комитета Азербайджанской Республики. http://www.stat.gov.az).

ISPC Generalization of scientific results, 
Наблюдается рост выпуска пищевых продукций в Азербайджане за последние годы. Так, в 2016 году была произведена продукция почти на 3,3 млрд. манатов или в эквиваленте 1,95 млрд. долларов США, которая имеет мощные резервы по увеличению объема производства и в том числе повышения экспортного потенциала.

\section{Conclusion}

Таким образом, можно прийти к мнению, что в Азербайджане имеется мощные запасы и потенциал развития деятельности ненефтяных сфер промышленности в контексте стратегических дорожных карт [11]. Но для этого необходимо, в первую очередь устранить имеющиеся проблемы, мешающие ускорению развития сферы ненефтяных промышленностей с применением продуктивных и эффективных механизмов регулирования той или иной сферой. Нуждается в расширении производственной мощности и более активной и привлекательной среды для привлечения иностранных компаний и инвесторов на разные сферы ненефтяных промышленностей. Путем создания свободных экономических зон, новых промышленных парков, промышленных зон [12;13;14].

\section{References:}

1. Aliyev SH.T. (2016) Kontseptual'nyye napravleniya usileniya promyshlennogo sektora i eksportnogo potentsiala $\mathrm{v}$ Azerbaydzhane // Zhurnal Shelkovoy puti, №4, 2016.- p. 35-42.

2. Aliyev SH.T. (2012) Sumgaitskiy industrial'nyy tsentr: ispol'zovaniye sushchestvuyushchego potentsiala, modernizatsiya i prioritety obnovleniya. Baku, «Nauka i obrazovaniye», 2012.- 196 p.

3. Aliyev SH.T. (2012) Otsenki i napravleniya rekonstruktsii khimicheskogo i neftekhimicheskogo kompleksa Azerbaydzhana. Baku, «Nauka i obrazovaniye», 2012.- $156 \mathrm{p}$.

4. (2014) Ukaz Prezidenta Azerbaydzhanskoy Respubliki o sozdanii i organizatsii deyatel'nosti promyshlennykh kvartalov. Baku, October 8, 2014.

5. Aliyev SH.T. (2016) Sovremennyye aspekty i napravleniya razvitiya neftekhimicheskogo kompleksa v Azerbaydzhane // Zhurnal Audit, 2016, №3.- p. 41-45.

6. (2017) Metallurgiya - Azerbaydzhan. Available: www.azerbaijans.com. (Accessed: 10.12.2017).
7. (2014) Polozheniye o promyshlennykh parkov. Utverzhdeno ukazam Prezidenta Azerbaydzhanskoy Respubliki ot 24 aprelya 2014

8. (2016) Strategicheskiye dorozhnyye karty po perspektivam natsional'noy ekonomiki Azerbaydzhanskoy Respubliki. Utverzhdeno Ukazom Prezidenta Azerbaydzhanskoy Respubliki ot 6 dekabrya 2016 goda.

9. (2017) Rasporyazheniye Prezidenta Azerbaydzhanskoy Respubliki ob uskorenii raboty po sozdaniyu svobodnykh ekonomicheskikh zon. Baku, 31 maya 2017 goda.

10. Aliyev SH.T. (2012) Problemy primeneniya osobykh ekonomicheskikh zon. Monografiya (Podgotovleno na osnove proyekta konkursa I Grant 2011 goda, Fonda Razvitiya Nauki pri Prezidenta Azerbaydzhanskoy Respubliki). Baku, 2012.- 360 p.

11. Aliyev SH.T. (2017) Vazhnost' osobykh ekonomicheskikh zon po realizatsii strategicheskikh dorozhnykh kart v Azerbaydzhane // Zhurnal «Geostrategiya», Baku, №01(37).- p. 32-35. 